\title{
Female discharges are more electrifying: spontaneous preference in the electric fish, Eigenmannia (Gymnotiformes, Teleostei)
}

\author{
B. Kramer and B. Otto \\ Zoologisches Institut der Universität, Universitätsstrasse 31, D-8400 Regensburg, Federal Republic of Germany \\ Received November 20, 1987 / Accepted March 11, 1988
}

Summary. The tropical South American teleost $E i$ genmannia lineata showed a spontaneous preference for the female type, compared with the male type, of its sexually dimorphic, weak-electric organ discharge (EOD). Female and male EODs differ in waveform and harmonic content. An isolated fish was simultaneously stimulated with digitally synthesized "natural" male and female EODs of equal peak-to-peak amplitudes, at $\pm 35 \mathrm{~Hz}$ frequency difference centered on its stable resting discharge frequency. The stimulus dipoles were arranged symmetrically to the right and left of the fish's hiding place. All stimulus conditions were permuted at random sequence. Among 11 fish tested, 8 showed a statistically significant preference for one stimulus, the female type, as measured by the amount of time a fish spent close to a stimulus dipole $(P<0.05$ in each fish, two-tailed). Thus female EODs rather than male EODs were more attractive to adult and juvenile fish of both sexes. It was also concluded that $E$. lineata is capable of discriminating female from male EODs by a complex sensory capacity requiring neither amplitude nor frequency cues. The EOD waveform changed very little within the ecological range of water conductivities (approximately $10-100 \mu \mathrm{S} \cdot \mathrm{cm}^{-1}$ ); the $P / N$-ratio (a waveform character based on zerocrossing intervals) depended only weakly, but significantly, on conductivity (negative correlation in all four fish). Also, the effect of temperature on EOD waveform was very weak: $Q_{10}$-values of the $P / N$-ratio were below but close to 1 in all fish $\left(27 \pm 5^{\circ} \mathrm{C}\right)$. Thus, it can be concluded that the EOD waveform is remarkably stable within widely changing conditions - even beyond the variation found in the field - and is therefore potentially useful as a social cue.

\section{Introduction}

The weakly electric fish Eigenmannia (Sternopygus) lineata Müller and Troschel (Gymnotiformes, Teleostei) of tropical South America discharges its electric organ in a wavelike fashion. Frequencies are extremely stable at rest, but vary among individuals - approximately $240-600 \mathrm{~Hz}$ at $27^{\circ} \mathrm{C}$ (Lissmann 1958). Mean frequencies of males and females differ significantly, but the statistical distributions widely overlap; frequency is therefore not considered a cue in mate recognition (Hopkins 1974a; Westby and Kirschbaum 1981).

Adult male and female electric organ discharges (EODs) differ in waveform and harmonic content: female EODs resemble sinusoids with a low content of higher harmonics; male EODs are narrow head-positive pulses superimposed on a head-negative baseline and contain strong overtones, especially the second one, counting the fundamental frequency as the first (Kramer 1985). There is little or no d.c. component; that is, averaged over time, there is little or no net current flow (Bennett 1968; B. Kramer, unpublished observations in four fish). The ratio of zero-crossing intervals of the Positive and Negative half-waves of an EOD cycle, Gottschalk's $P / N$-ratio, in adult males is about 0.4 to less than 0.6 , while that of females is greater than or equal to 0.6 to less than 1: water conductivity of $100 \mu \mathrm{S} \cdot \mathrm{cm}^{-1}, 27^{\circ} \mathrm{C}$ (Kramer 1985).

Kramer and Zupanc (1986) showed that trained fish are able to discriminate digitally synthesized male from female EODs, as well as other pairs of electric signals of equal frequencies and intensities in a food-rewarded, conditioned discrimination task. The discrimination was categorical and did not depend on intensity. In our study we report a spontaneous preference of E. lineata 



b
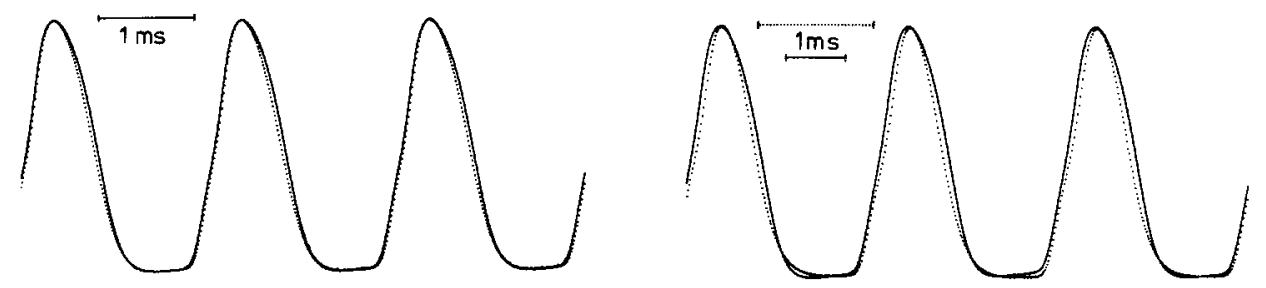

Fig. 1. a Electric organ discharge of male and female Eigenmannia lineata (left) with Fourier amplitude spectra (right) generated by a digital synthesizer and used for stimulation (recorded from the water). b Water conductivity (left) and temperature (right) barely affected the waveform of EOD. Left: line $=13 \mu \mathrm{S}$. $\mathrm{cm}^{-1}$; points $=106 \mu \mathrm{S} \cdot \mathrm{cm}^{-1}$ (both at $27^{\circ} \mathrm{C}$ ). Right: line $=$ $19.6^{\circ} \mathrm{C}$; points $=32.7^{\circ} \mathrm{C}$ (both at $101 \mu \mathrm{S} \cdot \mathrm{cm}^{-1}$ ). The EOD waves start and end at zero-crossings and are normalized to the same height. Bars = time scale

for synthesized female as compared to male EODs, with frequency and intensity cues not being influencing factors. [Eigenmannia can be trained to both the male and female EOD as the rewarded signal (Kramer and Zupanc 1986)]. We also investigated the dependence of Eigenmannia's EOD waveform on water conductivity and temperature in order to assess its stability and potential usefulness as a social cue in a variable environment.

\section{Methods}

Spontaneous preference for synthesized male or female EODs was tested in 11 Eigenmannia ( 13.5 to $38 \mathrm{~cm}$ in length; for photographs of fish of both sexes, see Kramer 1987). The test aquarium $(100 \times 50 \times 50 \mathrm{~cm}$ high; water conductivity, $105 \pm 5 \mu \mathrm{S} \cdot \mathrm{cm}^{-1}$; temperature, $27 \pm 0.7^{\circ} \mathrm{C}$ ) was provided with a shelter, a ball of aquatic vegetation loosely stuffed into a vertical cylinder made of coarse plastic mesh (diameter, $12 \mathrm{~cm}$; height, $8 \mathrm{~cm}$; open underneath). The cylinder containing the tropical aquatic moss ("Java moss", Vesicularia dubyana, Hypnobryales) that was occasionally replaced by synthetic filter wadding was suspended about $8 \mathrm{~cm}$ above the bare glass bottom next to the center of the aquarium's (long) front wall. This shelter was readily accepted as a hiding place by all fish.

At both ends of the aquarium an electric fish model (a dipole made of vertically oriented carbon rod electrodes; rod diameter, $0.5 \mathrm{~cm}$; rod length, $1 \mathrm{~cm}$; rod separation, $8 \mathrm{~cm}$ ) was centered $5 \mathrm{~cm}$ from and parallel to the short sides of the aquarium. Each dipole was connected to a microprocessor system (Kramer and Weymann 1987) that digitally synthesized male or female EODs according to instructions from a host computer (Digital Equipment Corporation's MINC-23).

The fish hiding in the centered shelter was stimulated simultaneously from the right and left with synthetic male and female EODs [maximum field strength at the fish's shelter was $17 \mu \mathrm{V}$. $\mathrm{cm}^{-1}$; field strength at the dipole was equivalent to an adult, gonadally ripe Eigenmannia female $(n=2)$ ]. The test fish's EOD frequency was measured immediately before each test with an accuracy better than $\pm 0.1 \mathrm{~Hz}$. The difference between the stimulus frequency and the test fish's frequency was $+35 \mathrm{~Hz}$ in half the trials, and $-35 \mathrm{~Hz}$ in the remainder. Stimulus rise/ fall time was $400 \mathrm{~ms}$.

In a randomized blocks design of experiments (Cochran and Cox 1957) two conditions in three factors were permuted: right/left dipole, male/female synthetic EOD, and frequency above/below the fish's EOD frequency. All eight stimulus combinations were used once a day; two were played back simultaneously for $5 \mathrm{~min}$ with 2 -h rest intervals. The stimulus combinations presented simultaneously were chosen such that the dipoles never had the same condition (for example, left dipole: female synthetic EOD, $+35 \mathrm{~Hz}$ relative to the fish frequency; right dipole: male synthetic EOD, $-35 \mathrm{~Hz}$ ). Four such simulta- 

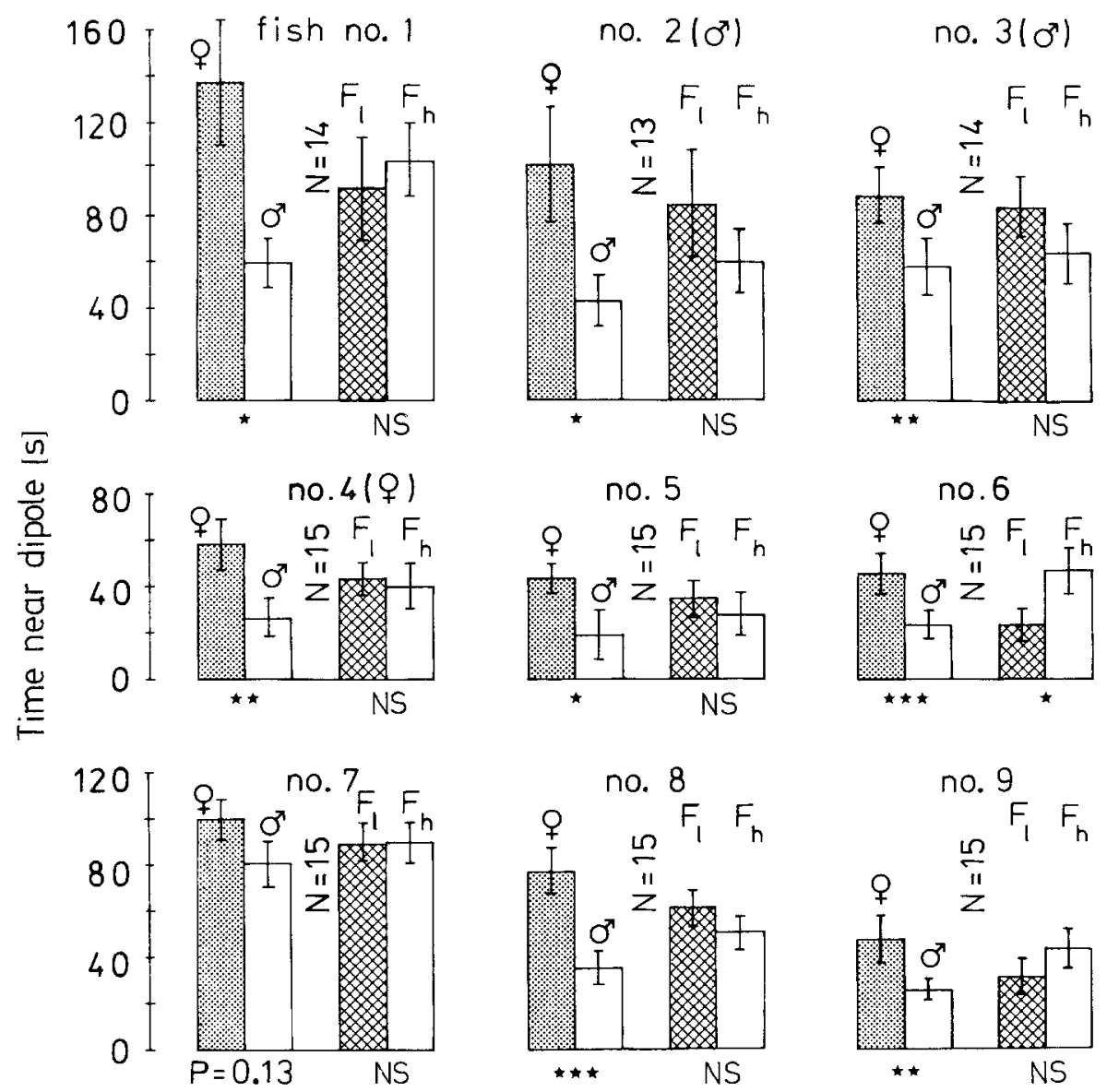

Fig. 2. Spontaneous preference of $E$. lineata for synthetic female EODs, as compared to synthetic male EODs (left column pairs marked "male" and "female"), given as means \pm standard error; shown individually for nine fish. There was no significant effect of frequency that varied $\pm 35 \mathrm{~Hz}$ from an experimental fish's EOD frequency (right hand pairs of columns, marked " $F_{1}$ " for stimulus frequency $35 \mathrm{~Hz}$ lower than fish frequency or " $F_{h}$ " for stimulus frequency $35 \mathrm{~Hz} \mathrm{higher} \mathrm{than} \mathrm{fish} \mathrm{frequency),} \mathrm{except}$ for fish no. 6 (which was attracted by "higher frequency" and "female synthetic EOD"). Ordinate: the time [s] the fish spent within $20 \mathrm{~cm}$ of a dipole emitting synthetic male or female EODs. NS difference nonsignificant; $P<0.05 ; * * P<0.02 ; * * * P<0.01$ (all two-tailed). $N$ number of days a complete random permutation of all stimulus conditions was run. Fish no. $1:$ length $17.7 \mathrm{~cm}$, $P / N$-ratio $=0.57$, night observations; fish no. 2 : adult male $38 \mathrm{~cm}, P / N=0.42$, day; fish no. $3:$ adult male $30 \mathrm{~cm}, P / N=0.42$, day; fish no. 4 : adult female $15.5 \mathrm{~cm}$, gravid with eggs, $P / N=0.60$, day; fish no. $5: 15.5 \mathrm{~cm}, P / N=0.72$, night; fish no. $6: 19.6 \mathrm{~cm}$, $P / N=0.75$, night; fish no. $7: 13.5 \mathrm{~cm}, P / N$ not determined, night; fish no. $8: 14.0 \mathrm{~cm}, P / N=0.82$, night; fish no. $9: 15.8 \mathrm{~cm}$, $P / N=0.70$, day

neous stimulus presentations were performed each day; the sequence of stimulus combinations was determined using Table 15.6 of random permutations of Cochran and Cox (1957); no column in that table was ever used more than once for any one fish.

The fish were allowed to swim freely and their behavior was observed in an overhead mirror placed on top of the aquarium at an angle of $45^{\circ}$. (The walls of the aquarium were covered by styrofoam sheets). There was neither reward nor punishment. Using two stopwatches, the time (s) was measured that the fish spent within a semicircle of $20 \mathrm{~cm}$ (drawn on brown cardboard underneath the glass-bottom of the aquarium) around each dipole. For statistical analyses (Sachs 1978) the daily means of the times a fish spent near a dipole were obtained by a two-factor analysis for signal type and frequency (the condition "stimulation from the right or left" was factored out).

Some fish did not move under light conditions (two incandescent $60 \mathrm{~W}$ light bulbs; these fish were tested during the dark phase of a reversed $12: 12 \mathrm{~h}$ light-dark cycle with dim red illumination (two red incandescent light bulbs used in photographic dark rooms) just sufficient for observation of the animals' movements.

Four isolated fish $(13.5,14.8,15.5$ and $15.8 \mathrm{~cm}$ long) were tested for EOD waveform stability, and had time (at least overnight) to adapt to a new condition (water conductivity or temperature). For methods of EOD recording and analysis, see Kramer (1985).

\section{Results}

How reliable is the difference between male and female EOD waveforms in a variable environment? Temperature and conductivity changes affected the EOD waveforms of four E. lineata only 
slightly (Fig. 1 b), except for the well-known correlation between discharge frequency and temperature (Lissmann 1958; Watanabe and Takeda 1963; Enger and Szabo 1968). The $Q_{10}$ of the $P / N$-ratio was close to but below 1 in all fish $(0.94,0.93$, $0.90,0.85)$ in the range of at least $27 \pm 5^{\circ} \mathrm{C}$. The $P / N$-ratio changed only slightly because as the EOD cycle shortened at increased temperatures $\left(Q_{10}=1.5\right.$, Enger and Szabo 1968) the EOD pulse duration also became shorter (even slightly more than proportionally).

Conductivity was also negatively correlated with $P / N$-ratio $(r=-0.84, P<0.01$; similar data on four fish pooled), but the slope of a leastsquares regression line was almost flat $(y=$ $-0.00093 x+0.82)$. Therefore, the mean $P / N$-ratio of 0.73 at $100 \mu \mathrm{S} \cdot \mathrm{cm}^{-1}$ increased only to 0.81 at $10 \mu \mathrm{S} \cdot \mathrm{cm}^{-1}$. The individual EOD waveforms of four Eigenmannia thus varied only slightly and were similarly affected by water conductivity and temperature.

Among 11 fish exposed to the paired stimulation of synthetic female and male EODs, 8 showed a statistically significant preference for female EODs $(P<0.05$, two-tailed; paired $t$-test; Wilcoxon matched-pairs signed-ranks test; Sachs 1978; 3 fish had no significant preference (Fig. 2). The preference for female EODs of one of these 3 fish might have become significant with continued experimentation $(P=0.13, n=15)$. All fish showed a side preference that was statistically balanced by the symmetrical experimental design.

Surprisingly, juvenile and adult fish of both sexes alike showed preference for female synthetic EODs. Frequency was irrelevant in all fish but one (which spent more time with a $+35 \mathrm{~Hz}$ than with a $-35 \mathrm{~Hz}$ synthetic EOD, relative to the fish's frequency; it also showed a strong preference for the female EOD). This fish had a slightly different head shape and was obtained from a different supplier. In two independent studies on full-grown, gonadally ripe Eigenmannia, the EOD frequencies of females were higher than those of males (Hagedorn and Heiligenberg 1985; Kramer 1985).

The adult males in particular showed signs of great excitement and vigorous behavior when in close contact with the active dipoles (for example, butting, rapidly swimming back and forth alongside a dipole, or rolling back and forth laterally over a dipole in parallel orientation). With the exception of the last form of behavior, similar behavior has been observed by Hopkins (1974a) and Hagedorn and Heiligenberg (1985) during agonistic encounters and during artificial stimulation via electrical dipoles.

\section{Discussion}

Closely related to any discussion of the mechanisms of species and mate recognition by EOD waveform cues are the questions of how the output from the electric organ is affected by changing water conditions, such as conductivity and temperature, and how variable the environmental conditions in the field are.

The Amazon basin - the principal home region of Eigenmannia species - is an equatorial lowland with minimal temperature fluctuations; the Amazon belongs to the thermally most stable waters on earth $\left(29 \pm 1^{\circ} \mathrm{C}\right.$ all year round; $30-31^{\circ} \mathrm{C}$ in the Rio Negro; Sioli 1984). Temperature may, however, vary beyond these limits in smaller streams (Kramer, personal observations). Three water types differing in electrolyte composition are found in the three major geochemical provinces (data from a 2-year study by Furch 1984): (1) the neutral "carbonate" or white-water $(\mathrm{pH}=6.9 \pm \mathrm{SD} 0.4)$ from the Western peripheral region with relatively high condúctivities up to $60 \pm \mathrm{SD} 18 \mu \mathrm{S} \cdot \mathrm{cm}^{-1}$; (2) the acid black-water from the northern peripheral region ( $\mathrm{pH}=5.1 \pm \mathrm{SD} 5.6)$ with an extremely low conductivity of only $9 \pm \mathrm{SD} 2 \mu \mathrm{S} \cdot \mathrm{cm}^{-1}$; (3) the extremely acid water of forest streams of the Central Amazon region $(\mathrm{pH}=4.5 \pm \mathrm{SD} 0.2)$ with a similarly low conductivity of $10 \pm \mathrm{SD} 3 \mu \mathrm{S} \cdot \mathrm{cm}^{-1}$. Eigenmannia species are commonly found in all three of these water types, although they seem to be most abundant in the nutrient-rich white-water (Kramer et al. 1981; Kramer, unpublished).

The individual EOD waveforms of four Eigenmannia were affected very little and in a similar manner by water conductivity and temperature (Fig. 1b). The conductivity result contrasts with that obtained in the African mormyrid Pollimyrus isidori (Bratton and Kramer, in press; for the effect of temperature on a mormyrid EOD, see Kramer and Westby (1985). The mormyrid pulse-EOD essentially is diphasic; the head-positive first phase current, which is neurochemically evoked by efferent nerve fibers from spinal electromotor neurons that are in contact with the posterior face of an electrocyte within the electric organ, electrically excites the opposite face, giving rise to the head-negative second phase current (Bennett and Grundfest 1961). In a medium of high resistance, first-phase voltage is maximized while current is reduced, thus failing to excite the second phase potential at a very high resistance (Bell et a1. 1976). All intergrades of EOD waveform change (due to the dependence of the second phase of the EOD on first phase current) are within the natural range of con- 
ductivities (Bratton and Kramer, in press). In Eigenmannia, however, the anterior, uninnervated face of an electrocyte is inexcitable and probably modified to pass capacitative current only (Bennett $1968,1971)$. This would explain the relative insensitivity of Eigenmannia's EOD waveform to conductivity changes, similar to the insensitivity of the first phase potential of a mormyrid pulse EOD. Eigenmannia's sexually dimorphic resting EODs are potentially useful as social cues for signalling sex or age because of their stability in a variable environment.

Eigenmannia species are gregarious fish (Lissmann 1961; Kramer, personal field observations); it therefore appears normal that experimentally isolated fish should join conspecifics (or electric dipoles simulating the presence of conspecifics). The preference of both females and juveniles for female synthetic EODs may be due to male aggressiveness (see Hagedorn and Heiligenberg 1985; Kramer 1985).

The present results independently support the findings of a conditioned discrimination capacity of synthetic male and female EODs (Kramer and Zupanc 1986). We conclude that in the context of food-associated stimuli (Kramer and Zupanc 1986) or social stimuli (this study) Eigenmannia uses a more complex type of signal analysis than it does in the context of the jamming avoidance response (JAR). All that is required for a signal analyzer subserving the JAR is the equivalent of a bandpass filter with low and high cutoff frequencies set at the fish's own EOD fundamental frequency, measuring the amplitude of any harmonic of another fish's signal that is sufficiently close in frequency to the fish's own fundamental frequency, passing only a sine wave (Kramer 1985). For discussions on how the fish can estimate the sign of the frequency difference, see Scheich $(1977 \mathrm{a}-\mathrm{c})$, as well as the review by Heiligenberg (1986) and Kramer (1987).

Although sufficient for the JAR, in the context of finding food and conspecifics, the fish seem to need more information than amplitude and frequency difference of only a single sine wave component of another fish's EOD. Frequency modulations (see Hopkins 1974 a ; Hagedorn and Heiligenberg 1985; Kramer 1987) are not needed for discrimination of male from female EODs. It is shown here again (see Kramer and Zupanc 1986) that $E i$ genmannia is capable of sensing the fine detail of its sexually dimorphic EOD even when amplitude and frequency are not factors and that this information may direct its behavior without training. The sensory mechanisms of that complex sensory capacity certainly deserve special attention (see Kramer 1985; Kramer and Zupanc 1986).

Mate recognition by its sex-specific difference in fundamental frequency was suggested in the low-frequency (about 50 to $150 \mathrm{~Hz}$ at $25^{\circ} \mathrm{C}$ ) wave fish Sternopygus macrurus (of the same family, Sternopygidae): males discharge at about one octave below females (Hopkins 1974b). As in Eigenmannia (Hagedorn and Heiligenberg 1985; Kramer 1985), the frequency difference is manifested only in the sexually mature, adult Sternopygus. Sternopygus' EOD has a very similar wave shape compared with that of Eigenmannia; Gottschalk (1981) suggested a sexual dimorphism in EOD waveform resembling the one found in Eigenmannia, with males displaying lower $P / N$-ratios than females. To date, we do not know the functional significance of this waveform variability in Sternopygus.

Discrimination and categorical recognition of artificial and natural pulse EODs of different waveforms was reported in a gymnotoid (Heiligenberg and Altes 1978) and in a mormyrid weakly electric fish (Hopkins and Bass 1981). However, Kramer (1985, pp. 63-64) argues that these conclusions need further support because alternative explanations, such as sensitivity differences, might also apply.

Using spontanous behaviour, this report confirms the results of conditioned discrimination experiments which showed that Eigenmannia discriminate their sexually dimorphic resting EODs. It is also shown that this information influences the fish's behavior in a biologically important manner - even outside a specifically reproductive context.

Acknowledgements. Supported by the Deutsche Forschungsgemeinschaft (SFB4/H1).

\section{References}

Bell CC, Bradbury J, Russell CJ (1976) The electric organ of a mormyrid as a current and voltage source. J Comp Physiol $110: 65-88$

Bennett MVL (1968) Neural control of electric organs. In: Ingle D (ed) The Central Nervous System and Fish Behavior. University of Chicago Press, Chicago, pp 147-169

Bennett MVL (1971) Electric organs. In: Hoar WS, Randall DJ (eds) Fish Physiology, vol V. Academic Press, London New York, pp 347-491

Bennett MVL, Grundfest $H$ (1961) Studies on the morphology and electrophysiology of electric organs. III. Electrophysiology of electric organs in mormyrids. In: Chagas C, Paes de Carvalho A (eds) Bioelectrogenesis. Elsevier, Amsterdam, pp 113-135

Bratton B, Kramer B (1988) Intraspecific variability of the pulse-type discharges of the electric fishes, Pollimyrus isidori and Petrocephalus bovei (Mormyridae, Teleostei), and their dependence on water conductivity. Exp Biol (in press) 
Cochran WG, Cox GM (1957) Experimental Designs, 2nd edn. Wiley \& Sons, New York

Enger PS, Szabo T (1968) Effect of temperature on discharge rates of the electric organ of some gymnotoids. Comp Biochem Physiol 27:625 627

Furch K (1984) Water chemistry of the Amazon basin: The distribution of chemical elements among freshwaters. In: Sioli $H$ (ed) The Amazon. Limnology and landscape ecology of a mighty tropical river and its basin. Junk Publishers, Dordrecht Boston Lancaster, pp 167-199

Gottschalk B (1981) Electrocommunication in gymnotoid wave fish: significance of a temporal feature in the electric organ discharge. In: Szabo T, Czéh G (eds) Sensory physiology of aquatic lower vertebrates. Adv Physiol Sci, vol 31. Pergamon Press/Akadémiai Kiadó, Budapest, pp 255-277

Hagedorn M, Heiligenberg W (1985) Court and spark: electric signals in the courtship and mating of gymnotoid fish. Anim Behav 33:254-265

Heiligenberg W (1986) Jamming avoidance responses: model systems for neuroethology. In: Bullock TH, Heiligenberg W (eds) Electroreception. Wiley \& Sons, New York, pp 613-649

Heiligenberg W, Altes RA (1978) Phase sensitivity in electroreception. Science 199: 1001-1004

Hopkins CD (1974a) Electric communication: functions in the social behavior of Eigenmannia virescens. Behaviour $50: 270-305$

Hopkins CD (1974b) Electric communication in the reproductive behavior of Sternopygus macrurus. Z Tierpsychol $35: 518-535$

Hopkins CD, Bass AH (1981) Temporal coding of species recognition signals in an electric fish. Science 212:85-87

Kramer B (1985) Jamming avoidance in the electric fish Eigenmannia: harmonic analysis of sexually dimorphic waves. $\mathrm{J}$ Exp Biol 119:41-69

Kramer B (1987) The sexually dimorphic jamming avoidance response in the electric fish Eigenmannia (Teleostei, Gymnotiformes). J Exp Biol 130:39-62

Kramer B, Kirschbaum F, Mark1 H (1981) Species specificity of electric organ discharges in a sympatric group of gymnotoid fish from Manaus (Amazonas). In: Szabo T, Czéh G (eds) Sensory physiology of aquatic lower vertebrates. Adv Physiol Sci, vol 31. Pergamon Press/Akadémiai Kiadó, Budapest, pp 195-219

Kramer B, Westby GWM (1985) No sex difference in the waveform of the pulse type electric fish, Gnathonemus petersii (Mormyridae). Experientia 41:1530-1531
Kramer B, Weymann D (1987) A microprocessor system for the digital synthesis of pulsed or continuous discharges of electric fish (or animal vocalizations). Behav Brain Res $23: 167-174$

Kramer B, Zupanc GKH (1986) Conditioned discrimination of electric waves differing only in form and harmonic content in the electric fish Eigenmannia. Naturwissenschaften $73: 679-680$

Lissmann $H$ (1958) On the function and evolution of electric organs in fish. J Exp Biol 35:156-191

Lissmann $\mathrm{H}$ (1961) Ecological studies on gymnotids. In: Chagas C, Paes de Carvalho A (eds) Bioelectrogenesis. Elsevier, Amsterdam, pp 215-226

Sachs L (1978) Angewandte Statistik. Statistische Methoden und ihre Anwendungen. Springer, Berlin Heidelberg New York

Scheich H (1977a) Neural basis of communication in the high frequency electric fish, Eigenmannia virescens (jamming avoidance response). I. Open loop experiments and the time domain concept of signal analysis. J Comp Physiol 113:181-206

Scheich H (1977b) Neural basis of communication in the high frequency electric fish, Eigenmannia virescens (jamming avoidance response). II. Jammed electroreceptor neurons in the lateral line nerve. J Comp Physiol 113:207-227

Scheich H (1977c) Neural basis of communication in the high frequency electric fish, Eigenmannia virescens (jamming avoidance response). III. Central integration in the sensory pathway and control of the pacemaker. J Comp Physiol 113:229-255

Sioli H (1983) Amazonien. Grundlagen der Ökologie des grössten tropischen Waldlandes. Wissenschaftliche Verlagsgesellschaft, Stuttgart

Sioli H (1984) The Amazon and its main affluents: Hydrography, morphology of the river courses, and river types. In: Sioli $\mathrm{H}$ (ed) The Amazon. Limnology and landscape ecology of a mighty tropical river and its basin. Junk Publishers, Dordrecht Boston Lancaster, pp 127-165

Watanabe A, Takeda K (1963) The change of discharge frequency by a.c. stimulus in a weak electric fish. J Exp Biol $40: 57-66$

Westby GWM, Kirschbaum F (1981) Sex differences in the electric organ discharge of Eigenmannia virescens and the effect of gonadal maturation. In: Szabo T, Czéh G (eds) Sensory physiology of aquatic lower vertebrates. Adv Physiol Sci, vol 31. Pergamon Press/Akadémiai Kiadó, Budapest, pp 179-194 